\title{
Teoria da Aprendizagem Significativa: elaboração e avaliação de aula virtual na plataforma Moodle
}

\author{
Theory of Significant Learning: development and evaluation of virtual classroom in Moodle platform
}

Teoría del Aprendizaje Significativo: creación y evaluación de aula virtual en la plataforma Moodle

\author{
Cláudia Prado', Débora Rodrigues Vaz", Denise Maria de Almeida" \\ ' Universidade de São Paulo, Escola de Enfermagem, Grupo de Estudos e Pesquisas de Tecnologia da \\ Informação nos Processos de Trabalho em Enfemagem - GEPETE. São Paulo-SP, Brasil. \\ " Hospital Beneficência Portuguesa de São Paulo, Escola de Enfermagem São Joaquim, Curso Técnico em Enfermagem. \\ Universidade de São Paulo, Escola de Enfermagem, Grupo de Estudos e Pesquisas de Tecnologia da Informação \\ nos Processos de Trabalho em Enfemagem - GEPETE. São Paulo-SP, Brasil.
}

Submissão: 05-08-2010 Aprovação: 23-01-2012

\section{RESUMO}

Esse estudo teve por objetivo elaborar e avaliar uma aula virtual sobre a Teoria da Aprendizagem Significativa para licenciandos em enfermagem. Trata-se de pesquisa aplicada, de produção tecnológica, desenvolvida em cinco fases: concepção e planejamento; desenvolvimento do conteúdo e designer instrucional; criação do material educacional, implantação no portal de aprendizagem Moodle (Modular Object-Oriented Dynamic Learning Environment) e avaliação por juízes. A aula foi elaborada e, após avaliação, foi aprovada pelos juízes mediante ajustes e passará a integrar a disciplina Metodologia do Ensino de Enfermagem I do Curso de Licenciatura da Escola de Enfermagem da USP. Acreditamos que a proposta deste estudo privilegia a formação do licenciando e, portanto, do futuro docente de enfermagem, de forma crítica e reflexiva, tendo como um dos componentes de seu perfil a perspectiva de buscar e utilizar novos conhecimentos para o desenvolvimento de sua prática profissional.

Descritores: Enfermagem; Ensino; Aprendizagem; Tecnologia educacional.

\begin{abstract}
This study aimed to develop and evaluate the virtual classroom on the Theory of Meaningful learning for undergraduates in nursing. It is applied research, production technology, developed in five phases: design and planning, content development and instructional designer, creation of educational materials, learning portal deployment in Moodle (Modular Object-Oriented Dynamic Learning Environment) and evaluation by judges. The class was developed and was approved, after evaluation by the judges, and adjustments, and will integrate the discipline Methodology of Nursing Teaching I, Degree Course Nursing School of USP. We believe that the purpose of this study favors the formation of the licensing and therefore the future of teaching nursing in a critical and reflective, with the components of a profile of the prospect of seeking and using new knowledge for the development of their professional practice.
\end{abstract} Key words: Nursing, teaching, learning, Educational technology.

\section{RESUMEN}

Este estudio tiene como objetivo desarrollar y evaluar el aula virtual en la teoría del aprendizaje significativo para los estudiantes de enfermería. Se trata de la investigación aplicada, la tecnología de producción, desarrollado en cinco fases: diseño y planificación, desarrollo de contenidos y diseñador instruccional, creación de materiales educativos, implementación en el portal Moodle (Modular Object-Oriented Dynamic Learning Environment) y evaluación por los jueces. La clase se desarrolló y fue aprobado después de la evaluación por los jueces a través de ajustes e integrará la metodología de la disciplina de Enfermería I Docencia Licenciatura Escuela de Enfermería de la USP. Creemos que la propuesta de este estudio favorece la formación de licenciados y, por lo tanto, el futuro de la enseñanza de enfermería, de forma crítica y reflexiva, teniendo como uno de los componentes de su perfil la perspectiva de la búsqueda y el uso de nuevos conocimientos para el desarrollo de su práctica profesional.

Palabras clave: Enfermería, la enseñanza, el aprendizaje, tecnologia educacional.

\section{AUTOR CORRESPONDENTE Claudia PradoＥ-mail: claupra@usp.br}




\section{INTRODUÇÃO}

O desenvolvimento de diferentes competências para ensinar e aprender neste início de século converge para uma ação pedagógica crítica e transformadora e a utilização de ferramentas e recursos das tecnologias educacionais pode significar aprender a aprender, modificando os paradigmas educacionais vigentes até então, e apontando a necessidade de modificações nos papéis dos sujeitos envolvidos neste processo.

O uso de ambientes virtuais de aprendizagem (AVA) tem sido considerado uma possibilidade pedagógica relevante em cursos de graduação, licenciatura, pós-graduação e capacitação de profissionais de enfermagem ${ }^{(1)}$. AVAs são sistemas computacionais disponíveis na Internet, que integram múltiplas mídias, linguagens e recursos, destinados ao suporte de atividades mediadas pelas tecnologias da informação e comunicação. Possibilitam a apresentação de informações de maneira organizada e o desenvolvimento de interações entre pessoas e objetos de conhecimento, bem como, elaboração e socialização de produções, vislumbrando atingir objetivos educacionais pré-determinados ${ }^{(2)}$.

Caracteriza-se como um espaço virtual que possibilita estabelecer um movimento dinâmico de construção e reconstrução do conhecimento por permitir a interação entre professor-aluno e aluno-aluno e o exercício da autonomia na exploração dos conteúdos e na resolução das situações propostas ${ }^{(3)}$.

A literatura tem apontado uma necessidade premente da promoção e inserção de propostas educacionais utilizando ambiente virtual de aprendizagem em enfermagem, visando fomentar o ensino a distância, por meio de novas tecnologias que possibilitam a realização de atividades individuais e proporcionam o ensino colaborativo, interativo e flexível aplicado à enfermagem ${ }^{(1,4-5)}$.

As pesquisas demonstram, também, a importância do desenvolvimento de estratégias de ensino utilizando recursos computacionais na formação e capacitação em enfermagem, devido à potencialidade em favorecer a dinâmica em sala de aula nos momentos presenciais, privilegiando as atividades práticas; incentivar a troca de experiências; possibilitar facilidade de acesso às ferramentas de navegação; permitir flexibilidade tanto de espaço quanto de tempo; organizar com clareza o conteúdo do curso; disponibilizar informações on-line e em tempo real aos graduandos e aos profissionais e proporcionar a realização de simulações ${ }^{(3,6-9)}$.

Apesar da importância da apropriação da competência tecnológica por parte dos enfermeiros, a inserção da enfermagem no panorama do ensino on-line brasileiro ainda é incipiente, havendo a necessidade das instituições de ensino superior adotarem políticas de investimento na capacitação tecnológica docente e discente, bem como na implementação de infraestrutura para o desenvolvimento de projetos de educação a distância estruturados em propostas pedagógicas que viabilizem a construção de competências, habilidades e conhecimento nas áreas de tecnologia da informação e de educação utilizando novas estratégias de ensino(10).

Nesse contexto, o planejamento e desenvolvimento de aulas e materiais instrucionais em ambientes virtuais de aprendizagem tem sido uma proposta do Curso de Licenciatura em Enfermagem da Escola de Enfermagem da Universidade de São Paulo. Elegeu-se como tema da primeira aula virtual a Teoria da Aprendizagem Significativa (TAS), pois esta se apresenta como importante referencial teórico para o ensino de enfermagem.

Considera-se que a aprendizagem é significativa quando uma nova informação adquire significado para o aprendiz através da ancoragem desta em aspectos relevantes de sua estrutura cognitiva preexistente. Caracteriza-se pela interação entre o novo conhecimento e o prévio ${ }^{(11)}$. Para que a aprendizagem significativa ocorra três condições se fazem necessárias, disposição para o aprender; presença de conceitos relevantes na estrutura cognitiva do aprendiz e material didático com significado lógico e psicológico ${ }^{(11)}$.

A motivação para a inserção de aulas virtuais foi a crença de que a educação mediada pela tecnologia, em especial o uso dos ambientes virtuais de aprendizagem, leva o estudante a construir seu próprio conhecimento mediado por intervenções do professor. Estes recursos fazem parte do momento histórico vivenciado por eles e, por esta razão, podem tornar a aprendizagem mais significativa e prazerosa.

Cabe destacar, ainda, que projetos pedagógicos inovadores têm como meta criar e utilizar estratégias pedagógicas que envolvam e mantenham a mobilização não só de docentes, corpo técnico e administrativo da escola, mas também dos alunos, na perspectiva da melhoria da qualidade do curso.

Neste sentido, ao considerarmos as tecnologias educacionais e os novos paradigmas vigentes na educação em enfermagem apontamos a relevância deste estudo na medida em que relata a elaboração e avaliação de uma aula virtual sobre a Teoria da Aprendizagem Significativa, considerando a sua significação para o ensino de enfermagem, especialmente para a formação pedagógica de licenciandos, futuros docentes de enfermagem.

Acreditamos que a proposta deste estudo privilegia a formação do aluno e, portanto futuro enfermeiro e docente de enfermagem, de forma crítica e reflexiva, tendo como um dos componentes de seu perfil a perspectiva de buscar e utilizar novos conhecimentos para o desenvolvimento da prática profissional, especialmente na área do ensino de enfermagem.

\section{OBJETIVO}

Elaborar e avaliar a aula virtual sobre a "Teoria da Aprendizagem significativa" disponibilizada na plataforma Moodle.

\section{PERCURSO METODOLÓGICO}

Tratou-se de uma pesquisa aplicada, de produção tecnológica, para elaboração e avaliação de uma aula virtual disponibilizada em ambiente virtual de aprendizagem para licenciandos de enfermagem da disciplina Metodologia do Ensino de Enfermagem II, do Curso de Licenciatura em Enfermagem da Escola de Enfermagem da Universidade de São Paulo. Esta modalidade de pesquisa objetiva a criação de novos produtos, otimização da eficiência de produtos já existentes e busca soluções para problemas vivenciados pelo pesquisador ${ }^{(12-13)}$. 
O presente estudo foi aprovado pelo Comitê de Ética em Pesquisa (Processo no. 771/2008/CEP-EEUSP) e pela Comissão de Pesquisa (Processo no. 85/2008/CPq/EEUSP) da Escola de Enfermagem da USP e desenvolvido em quatro fases: concepção e planejamento; desenvolvimento do conteúdo e design instrucional; criação do material educacional e implantação no portal de aprendizagem ${ }^{(3-4,14-15)}$.

\section{a) Concepção e planejamento}

A concepção pedagógica e planejamento da aula virtual teve início em fevereiro de 2009. Nessa fase deu-se a escolha do tema da aula considerando o público-alvo (alunos do Curso de Licenciatura em Enfermagem), na intenção de adequá-lo às características, necessidades de aprendizagem e interesses desses sujeitos; a definição dos objetivos educacionais da aula e o levantamento dos recursos necessários ao desenvolvimento do projeto.

\section{b) Desenvolvimento do conteúdo e design instrucional}

Esta fase contemplou o levantamento bibliográfico nas bases de dados Literatura Latino-Americana e do Caribe em Ciências da Saúde - LILACS, Literatura Internacional em Ciências da Saúde - MEDLINE e Scientific Eletronic Library Online e Biblioteca Cochrane - SciELO, visando identificar publicações que pudessem compor o referencial teórico da aula. Foram selecionadas as mídias (animações, links, imagens) que melhor se adequaram ao tema e aos objetivos educacionais. Definiu-se também as formas de avaliação e as estratégias para motivar os estudantes no percurso da aula.

\section{c) Criação do material educacional}

Após o levantamento bibliográfico deu-se a confecção do material instrucional, elaboração de situação-problema, criação de mídias a serem utilizadas no ambiente virtual e dos procedimentos didáticos. Esse processo foi construído através de parceria entre as pesquisadoras, um designer gráfico e uma pedagoga.

\section{d) Implantação no portal de aprendizagem}

O ambiente de apoio escolhido para o desenvolvimento da proposta educacional foi a plataforma Moodle (Modular Object-Oriented Dynamic Learning Environment - Moodle) - software livre, desenvolvido de forma colaborativa por designers e programadores. Este ambiente permite a interação, participação e cooperação dos alunos para a construção do conhecimento, a produção e o gerenciamento de atividades educacionais baseadas na internet e/ou em redes locais.

\section{e) Avaliação pelos juízes}

Com a finalidade de promover ajustes e correções, antes da disponibilização aos licenciandos, a aula foi submetida à avaliação por uma banca de juízes. A banca foi formada por quatro docentes da área de enfermagem com experiência no uso das tecnologias educacionais, que possuem de 10 a 23 anos de formados; 01 a 20 anos de experiência como docente; títulos de especialista, mestre, doutor e livre-docente. Após assinatura do Termo de Consentimento Livre e Esclarecido, foi fornecida a senha de acesso a plataforma.
A avaliação da aula deu-se por meio de um instrumento construído pelas autoras, o qual foi elaborado a partir de instrumentos testados e comprovados quanto à sua eficiência por pesquisadores nesta área do conhecimento ${ }^{(14-15-16)}$. O instrumento é composto das seguintes itens de análise: manuseio do ambiente virtual (acessibilidade, navegabilidade e tutoriais); tema proposto (relevância para o público-alvo e atualidade); textos e/ou hipertextos (quantidade de informações, profundidade da abordagem, utilidade para o público-alvo, coerência com o tema da disciplina, clareza das informações, pertinência e atualidade das referências e relevância e confiabilidade dos links); Imagens (quantidade, criatividade, atratividade e relevância para a aprendizagem); interatividade (fórum, diário e animações) e qualidade da interface (uso do espaço da tela visualização dos conteúdos, padrão de cores, tipo e tamanho das fontes tipográficas, vídeos, fotos, figuras, som e animação).

A avaliação deu-se por meio da atribuição de conceitos (ótimo, bom, regular ou ruim), para cada um dos itens analisados sendo considerados aceitáveis os itens bom e ótimo. No instrumento foi disponibilizado um espaço para os juízes, justificarem os conceitos atribuídos e indicarem sugestões para a melhoria da aula.

\section{RESULTADOS E DISCUSSÃO}

A aula virtual sobre a Teoria da Aprendizagem Significativa foi elaborada e inserida na plataforma Moodle, na página da disciplina Metodologia do Ensino de Enfermagem II do Curso de Licenciatura em Enfermagem da Escola de Enfermagem da Universidade de São Paulo e avaliada pela banca de juízes.

\section{A - ELABORAÇÃO DA AULA VIRTUAL}

3 3a. aula - 03 setembro 2009 (aula virtual)

APRENDIZAGEM SIGNIFICATIVA

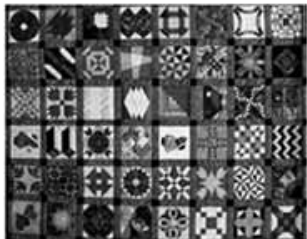

$$
\begin{aligned}
& \text { 园 Tutora virtual } \\
& \text { c. ATTLS } \\
& \text { 9] Video "Mente inovadora" } \\
& \text { 因 Dilema de Ana } \\
& \text { (0) Teoria da Aprendizagem Significativa - TAS } \\
& \text { 2] Video "O peixe afogado" } \\
& \text { Thórum - "Dilema de Ana" } \\
& 9 \text { Video "Aprender a aprender" } \\
& \text { Tún Fórum "Aprender a aprender" } \\
& \square \text { Recordando a TAS } \\
& \text { [2. Avaliando essa experiência } \\
& \text { c] COLLES } \\
& \checkmark \text { Biblioteca TAS } \\
& \text { TÉ Förum de dúvidas }
\end{aligned}
$$

Figura 1 - Tela da aula virtual "Teoria da Aprendizagem Significativa" 
Para a elaboração e organização dos conteúdos da aula virtual adotou-se como referencial pedagógico a metodologia dialética que concebe a construção do conhecimento em três fases: Mobilização, Construção e Síntese ${ }^{(17)}$.

FASE 1 - Mobilização do conhecimento - as atividades e materiais educacionais possibilitam ao estudante o primeiro contato com o tema e a mobilização para o estudo do mesmo. Os conteúdos foram dispostos da seguinte maneira:

Rota de aprendizagem - A rota de aprendizagem tem por finalidade estruturar o caminho a ser trilhado pelo estudante no decorrer da aula estabelecendo uma comunicação tridimensional entre aluno/professor/conhecimento. Serve como uma ponte, ligando o que o professor deseja e precisa ensinar com aquilo que o estudante precisa aprender ${ }^{(18)}$.

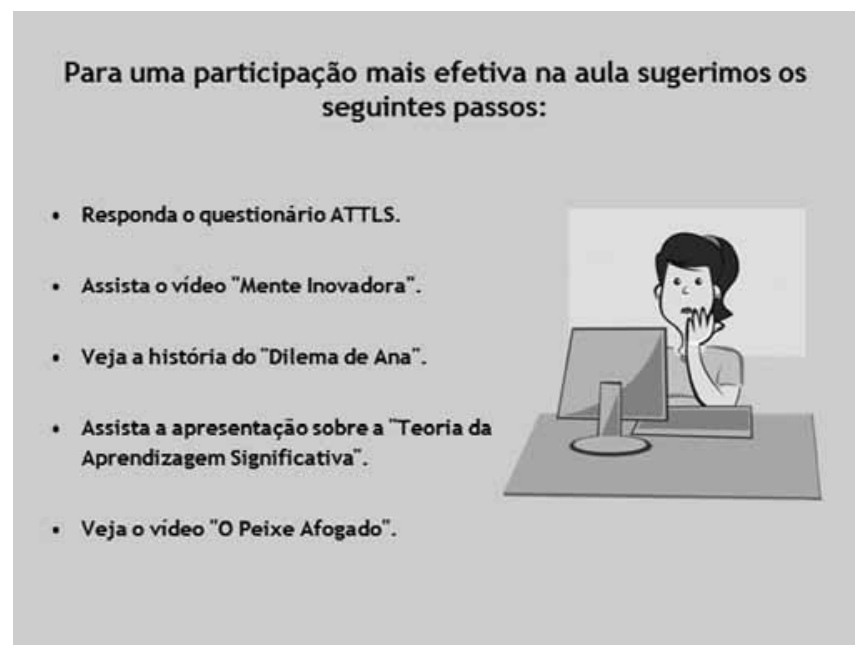

Figura 2 - Tela da Rota de Aprendizagem

Tutora virtual - Para conduzir o leitor pela rota, optou-se pela criação da tutora virtual, chamada pelas pesquisadoras de "Nina", a qual foi embasada em referencial teórico vindo da construção de marcas na publicidade, segundo o qual personagens podem ser poderosos instrumentos para estabelecer um elo de relacionamento mais atraente e forte ${ }^{(19)}$, e promover também a humanização do ambiente ${ }^{(20)}$. A tutora virtual tem também como proposta criar uma identidade visual integrando as demais aulas que farão parte da disciplina criando a percepção de que todas as aulas pertencem à mesma disciplina.

Vídeo Mente Inovadora - O vídeo "Mente inovadora Aprendizagem significativa", com 5'37" de duração foi selecionado pelas autoras no Youtube (Disponível em < http:// www.youtube.com/watch? $v=$ Ngwmr4e0sDc\&feature $=$ relat ed $>$ ), visto que seu conteúdo aborda o processo de aprendizagem no mundo contemporâneo e o aprender a aprender. Seu objetivo foi levar o estudante à reflexão sobre o tema. Seu conteúdo

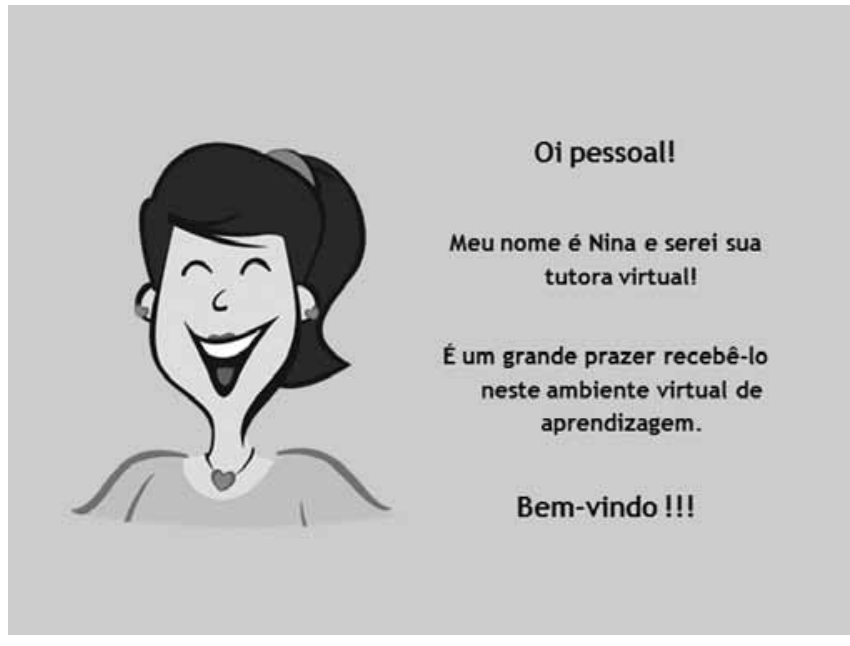

Figura 3 - Tela da tutora virtual

Dilema de Ana - Elaborado sob a forma de situação-problema, relacionada ao contexto de futuros docentes de enfermagem, visa provocar conflitos cognitivos (desequilíbrios) nos estudantes que os levem a empreender uma busca pessoal para a resolução do problema, permitindo assim uma aprendizagem significativa. Disponibilizado em slides, o Dilema de Ana integra imagens aos textos combinando-se a linguagem das imagens a linguagem textual, para tornar a leitura do material mais atraente e gerar nos estudantes maior curiosidade e interesse em prosseguir. Este material foi desenvolvido com a colaboração e supervisão de um designer gráfico que apresentou aos pesquisadores alguns princípios norteadores para a construção do material. Utilização de:

$\checkmark \quad$ cores como plano de fundo dos slides (até seis cores complementares) considerando o emprego de contraste entre este e a cor da fonte, pois o uso de cores como coadjuvantes promovem a quebra da monotonia, favorecendo a leiturabilidade e legibilidade;

$\checkmark$ de pensamento visual: transformação de conceitos em imagens (fotos ou imagens);

$\checkmark$ de metáforas;

$\checkmark$ de imagens em diferentes posicionamentos nos slides de forma a criar um dinamismo na apresentação, provocando o movimento dos olhos, mesmo a apresentação sendo estática;

$\checkmark \quad$ imagem sempre vinculada (alinhada) a algum ponto do texto;

$\checkmark \quad$ cor do plano de fundo do slide vinculada à cor da imagem ou vice-versa;

$\checkmark \quad$ emprego de fonte sem serifa para facilitar a leiturabilidade e legibilidade.

A fonte escolhida (Trebuchet MS) é uma família tipográfica sem-serifa desenhada por Vincent Connare para a Microsoft Corporation em 1996 para emprego em meios digitais ${ }^{(25)}$. Nos textos dos slides privilegiou-se o tom de diálogo simulando uma conversa entre o professor e o estudante como estratégia de inclusão destes. 
FASE 2 - Construção do conhecimento - Foram propostas atividades para possibilitar ao aluno o início da construção do seu conhecimento sobre o tema.

Teoria da Aprendizagem Significativa - TAS - Para a confecção desse material adotou-se o referencial teórico de David Ausubel, disponibilizado em 27 telas as quais seguiram os mesmos princípios norteadores adotados na elaboração das telas do "Dilema de Ana".

Vídeo O Peixe Afogado - A história "O peixe afogado", com 3' 14" de duração, faz parte do vídeo "10 Histórias exemplares", do prof. Celso Antunes, produzido pela Atta Mídia e Educação, e traz um exemplo de aprendizagem mecânica e aprendizagem significativa de forma lúdica e instigante ao aprendiz.

Fórum "Dilema de Ana" - espaço criado para a discussão e troca de informações que ajudem na resolução do dilema. A escolha da ferramenta fórum foi devido ao seu potencial para promover a interação social desencadeadora do aprendizado, estimulando a cooperação e possibilitando a reelaboração do conhecimento através do processo de mediação. Constitui-se num espaço privilegiado de aprendizagem e construção do conhecimento.

FASE 3 - Síntese do conhecimento - Foram propostas atividades com a intenção de estimular o estudante a resgatar e sintetizar o que foi apreendido nas fases anteriores.

Vídeo "Aprender a aprender" - Produzido em 2005 pela Savannah College of Art and Design, dirigido por Josh Burton, com 7'50" de duração, o vídeo foi selecionado do Youtube (Disponível em <http://www.youtube.com/watch?v=Pz4vQM Emzl >), por apresentar um conteúdo compatível com o tema da aula de uma maneira divertida e estimulante. Esse vídeo foi avaliado por 5 juízes, enfermeiros docentes e alunos de graduação e pós-graduação em enfermagem (1 doutora, 1 doutorando, 1 mestre, 1 mestranda e 1 graduanda) quanto a presença de imagens e/ou situações que permitam a identificação das condições básicas para a efetivação da aprendizagem significativa sendo aprovado por unanimidade. Dentre os comentários destacamos: "Acredito que o vídeo traduza de maneira excelente o processo de aprendizagem"; "O vídeo retrata que o processo de aprendizagem envolve a construção de um novo saber do qual você precisa se apropriar"; "Esta metáfora revela que no processo de aprendizagem significativa o aprendiz pode transformar a realidade e sentir prazer e satisfação com o resultado".

Fórum "Aprender a Aprender" - após assistir ao vídeo "Aprender a Aprender" os estudantes deverão responder a seguinte proposição: "Estabeleça uma relação entre as imagens do vídeo e as condições básicas para que a aprendizagem significativa se efetue".

Fórum de dúvidas - Durante todo o período da aula este fórum permanecerá aberto como um canal de comunicação entre os tutores e os estudantes.
Biblioteca Virtual - A biblioteca virtual disponibiliza aos estudantes, material suplementar, para aprofundamento da temática. Para estimular a colaboração, os estudantes poderão enviar materiais para ampliação o acervo.

\section{Avaliação da aprendizagem}

Foram disponibilizadas algumas ferramentas para a avaliação do processo de aprendizagem dos estudantes:

ATTLS (Attitudes Towards Thinking and Learning Survey) - Questionário, disponível na plataforma Moodle, composto por 20 questões de múltipla escolha, que permite investigar a postura dos participantes frente a aprendizagem e a reflexão crítica.

Recordando a TAS - quizz com cinco questões conceituais de múltipla escolha sobre a TAS.

Avaliando essa experiência - foi selecionada a ferramenta "Diário" na qual os aprendizes responderão a seguinte questão norteadora: "Como foi, para você, a experiência dessa aula virtual?" Essa atividade irá possibilitar aos autores um feedback para reconstrução e aprimoramento da aula a partir da percepção dos estudantes.

COLLES (Constructivist OnLine Learning Environment Survey)- Questionário disponível na plataforma Moodle, composto por 24 declarações distribuídas em 6 grupos, cada um relativo a um ponto crucial de avaliação da qualidade do processo de aprendizagem no ambiente virtual: Relevância: Quão relevante é o processo de aprendizagem para a vida profissional do participante? Reflexão Crítica: As atividades online estimulam os processos de reflexão crítica dos alunos? Interação: Até que ponto os diálogos online são ricos, considerando um contexto educativo? Apoio dos Tutores: Em que medida as atividades dos tutores favorecem o desenvolvimento de habilidades de participação no curso online? Apoio dos Colegas: Os colegas se apóiam e se encorajam mutuamente em modo sensível? Compreensão: Os participantes e os tutores compreendem bem as comunicações recíprocas?

\section{Instrumentos de avaliação}

Com a intenção de acompanhar o processo de aprendizagem dos estudantes, foram elaborados três instrumentos de avaliação. Para cada um foram determinados critérios e atribuídas notas, visto que esta aula fará parte da composição da nota final dos estudantes na disciplina Metodologia de Ensino de Enfermagem II.

a) Instrumento gerencial - identificação do percurso percorrido pelo estudante mediante a rota de aprendizagem proposta;

b) Fórum Dilema de Ana - elaboração de estratégia de ensino para resolução do dilema de Ana que contemple os princípios da TAS;

c) Fórum Aprender a Aprender - identificação, no vídeo, das condições básicas para que a aprendizagem significativa se efetue. 


\section{B - AVALIAÇÃO DA AULA VIRTUAL}

A seguir, apresentamos os conceitos atribuídos pelos juízes para item analisado.
Os itens manuseio do ambiente virtual (acessibilidade, orientações para navegação); tema proposto (relevância para o público-alvo e atualidade); textos e/ou hipertextos (quantidade de informações, profundidade da abordagem, utilidade para

\begin{tabular}{|c|c|c|c|c|c|}
\hline Manuseio do Ambiente Virtual & Ótimo & Bom & Regular & Ruim & Não Avaliado \\
\hline Acessibilidade & 2 & 2 & 0 & 0 & 0 \\
\hline Navegabilidade & 1 & 2 & 1 & 0 & 0 \\
\hline Orientações de Navegação & 1 & 3 & 0 & 0 & 0 \\
\hline Tema Proposto & Ótimo & Bom & Regular & Ruim & Não Avaliado \\
\hline Relevância & 3 & 1 & 0 & 0 & 0 \\
\hline Atualidade & 2 & 2 & 0 & 0 & 0 \\
\hline Conteúdo - textos/hipertextos & Ótimo & Bom & Regular & Ruim & Não Avaliado \\
\hline Quantidade de informações & 1 & 3 & 0 & 0 & 0 \\
\hline Profundidade da abordagem & 3 & 1 & 0 & 0 & 0 \\
\hline Utilidade público-alvo & 3 & 1 & 0 & 0 & 0 \\
\hline Coerência com o tema do módulo & 3 & 1 & 0 & 0 & 0 \\
\hline Clareza das informações & 1 & 3 & 0 & 0 & 0 \\
\hline Pertinência das referências & 2 & 2 & 0 & 0 & 0 \\
\hline Atualidade das referências & 3 & 1 & 0 & 0 & 0 \\
\hline Links para informações & 2 & 1 & 1 & 0 & 0 \\
\hline Conteúdo - imagens & Ótimo & Bom & Regular & Ruim & Não Avaliado \\
\hline Quantidade & 0 & 4 & 0 & 0 & 0 \\
\hline Criatividade & 3 & 1 & 0 & 0 & 0 \\
\hline Atratividade & 3 & 1 & 0 & 0 & 0 \\
\hline Significância para a aprendizagem & 3 & 1 & 0 & 0 & 0 \\
\hline Interatividade & Ótimo & Bom & Regular & Ruim & Não Avaliado \\
\hline Fórum de discussão & 1 & 3 & 0 & 0 & 0 \\
\hline Diário & 1 & 1 & 0 & 0 & 2 \\
\hline Animações & 3 & 0 & 0 & 0 & 1 \\
\hline Qualidade da Interface & Ótimo & Bom & Regular & Ruim & Não Avaliado \\
\hline Uso do espaço da tela & 2 & 2 & 0 & 0 & 0 \\
\hline Visualização dos conteúdos & 2 & 2 & 0 & 0 & 0 \\
\hline Padrão de cores & 2 & 2 & 0 & 0 & 0 \\
\hline Tipo de letra & 2 & 2 & 0 & 0 & 0 \\
\hline Tamanho de letra & 2 & 1 & 1 & 0 & 0 \\
\hline Vídeos & 4 & 0 & 0 & 0 & 0 \\
\hline Fotos & 4 & 0 & 0 & 0 & 0 \\
\hline Figuras & 3 & 1 & 0 & 0 & 0 \\
\hline Som & 2 & 2 & 0 & 0 & 0 \\
\hline Animações & 3 & 0 & 0 & 0 & 1 \\
\hline
\end{tabular}

Quadro 1 - Distribuição dos conceitos atribuídos pelos juízes aos itens analisadas. 
o público-alvo, coerência com o tema da disciplina, clareza das informações, pertinência e atualidade das referências); imagens (quantidade, criatividade, atratividade e relevância para a aprendizagem); interatividade (fórum, animações) e qualidade da interface (uso do espaço da tela, visualização dos conteúdos, padrão de cores, tipo das fontes tipográficas, vídeos, fotos, figuras, som e animação) receberam conceitos entre bom e ótimo apontando que na perspectiva dos juízes a aula atinge seus propósitos como indicam as falas:

"Penso que esta aula cumpriu o seu objetivo, levou os alunos a construção coletiva do conhecimento através da interatividade das atividades propostas".

"Seguiu perfeitamente o modelo pedagógico da dialética onde partiu da provocação dos alunos levando-os ao conhecimento final ou síntese do assunto".

"A seqüência dos conteúdos está bem organizada".

"A rota de aprendizagem ficou muito boa ..."

"As imagens caracterizam muito bem o sentido da aula ..."

Os itens navegabilidade, links para informações e tamanho das letras na interface receberam conceito regular por parte de um juiz:

"Mesmo com a internet banda larga alguns vídeo são um pouco pesados e inúmeras vezes tive problemas para assistir por inteiro."

"A maior dificuldade foi a acessibilidade dos links. Alguns deles em alguns momentos fora do ar e outras vezes com dificuldade de aceso."
"Sugiro o aumento do tamanho das letras da apresentação da disciplina e em todos os demais ícones, pois a leitura fica mais rápida e mais compreensível..."

Após os ajustes quanto aos itens acima descritos a aula passará a integrar a disciplina Metodologia do Ensino de Enfermagem I do Curso de Licenciatura e também disciplinas da área de Educação em Enfermagem dos Cursos de Graduação e Pós-graduação da Escola de Enfermagem da USP.

\section{CONSIDERAÇÕES FINAIS}

Considera-se que os objetivos propostos neste estudo foram atingidos na medida em que foi elaborado, avaliado e aprovado pelos juízes um produto tecnológico de impacto relevante, considerando-se a demanda pelo uso dos ambientes virtuais no ensino de enfermagem.

Acreditamos na incorporação de diferentes mídias no processo de construção e re-construção dos saberes na enfermagem, visto que estas proporcionam o aprendizado a partir das múltiplas potencialidades, capacidades e interesses dos educandos, e contribuem significativamente para um aprendizado coletivo e, por fim, na viabilidade de sua construção. A aula virtual vai ao encontro do pensamento pedagógico atual ao promover a aprendizagem significativa do estudante e, concomitantemente, capacitá-lo para a inclusão das tecnologias digitais em sua futura prática pedagógica.

Pretendemos, com estes resultados, estimular tanto docentes quanto estudantes ao uso das novas tecnologias educacionais, abrindo novas perspectivas nos cursos de graduação, licenciatura, pós-graduação e educação profissional por meio da construção e utilização de hipermídias em ambientes virtuais de aprendizagem, ou seja, adotando propostas pedagógicas inovadoras que permitam a aprendizagem significativa.

\section{REFERÊNCIAS}

1. Camacho ACLF. Análise das publicações nacionais sobre educação à distância na enfermagem. Rev. Bras. Enferm. 2009; 62(4): 588-93.

2. Almeida MEB. Educação a distância na internet: abordagens e contribuições dos ambientes digitais de aprendizagem. Educ. e Pesqui., 2003; 29(2): 327-40.

3. Costa JB; Peres HHC; Rogenski NMB; Baptista CMC. Proposta educacional on-line sobre úlcera por pressão para alunos e profissionais de enfermagem. Acta Paul Enferm 2009; 22(5): 607-11.

4. Caetano KC; Peres HHC. Metodologia para estruturação de hipertexto aplicado ao ensino de enfermagem. Acta Paul. Enferm. 2007; 20(2): 175-9.

5. Costa, JB; Peres, HHC. Desenvolvimento de proposta educacional on-line sobre úlceras por pressão para enfermagem [monografia]. São Paulo (SP): Escola de Enfermagem da Universidade de São Paulo; 2007.

6. Cogo ALP, Silveira DT, Lirio AM, Severo CL. A utilização de ambiente virtual de aprendizagem no ensino de suporte básico e avançado de vida. Rev Gaúcha de Enferm 2003; 24 (3): 373-9.

7. Dias DC, Cassiani SHB. Educação sem distancias: utilização do WebCT como ferramenta de apoio para o ensino da Terapia Intravenosa na graduação em enfermagem. Rev Bras Enferm 2003; 56 (4): 443-6.

8. Zem-Mascarenhas $\mathrm{SH}$, Cassiani SHB. Desenvolvimento e avaliação de um software educacional para o ensino de enfermagem pediátrica. [tese] São Paulo (SP): Escola de Enfermagem de Ribeirão Preto, Universidade de São Paulo; 2000. [citado em: 03 mai 2006] Disponível em: 
9. <http://www.scielo.br/scielo.php?script=sci_arttext\&pid $=$ S010411692001000600003\&lng $=$ pt\&nrm $=$ iso $>$.

10. Juliani CMCM. Tecnologia educacional: produção e avaliação do site escala de pessoal de enfermagem. Rev Interface Comunic Saúde Educ 2003 ago [citado em: 05 mai 2006]; 13 (7): 161-2. Disponível em: <http://www. interface.org.br/indice.asp?nCodVol =13\#Ateses $>$.

11. Rodrigues RCV; Peres HHC. Panorama brasileiro do ensino de Enfermagem On-line. Rev. Esc. Enferm. USP; 2008;42(2): 298-304.

12. Moreira, MA. Versão revisada e estendida de conferência proferida no III Encontro Internacional sobre Aprendizagem Significativa, Lisboa (Peniche), 11 a 15 de setembro de 2000. Publicada nas Atas desse Encontro, p.p. 3345, com o título original de Aprendizagem significativa subversiva.

13. Parra Filho D; Santos JÁ. Metodologia científica. São Paulo: Futura; 1998.

14. Polit DF; Beck CT; Hungler BP. Fundamentos de pesquisa em enfermagem, 5a. ed. Porto Alegre: Artes Médicas; 2004.

15. Rodrigues, RCV. Ambiente virtual de aprendizagem em reanimação cardiorrespiratória em neonatologia.
Dissertação (Mestrado). São Paulo (SP): Escola de Enfermagem da Universidade de São Paulo; 2008.

16. Alavarce DC. Elaboração de uma hipermídia educacional para o ensino do procedimento de medida da pressão arterial para utilização em ambiente digital de aprendizagem [dissertação]. São Paulo (SP): Escola de Enfermagem da Universidade de São Paulo; 2007.

17. Caetano, KC. Desenvolvimento e avaliação de um ambiente de aprendizagem virtual em administração em enfermagem. Dissertação (Mestrado). São Paulo (SP): Escola de Enfermagem da Universidade de São Paulo; 200.

18. Vasconcelos CS. Metodologia dialética em sala de aula. Revista AEC 1992; 21(83): 28-55.

19. Schneider El; Medeiros LF; Urbanetz ST. O Aprender e o Ensinar em EaD por meio de Rotas de Aprendizagem. In: Anais do $15^{\circ}$ Congresso Internacional Associação Brasileira de Educação a Distância; 2009 set 27-30; Fortaleza (CE), Brasil. Local: Abed; 2009. p. 1-13. [citado em 15 nov 2009]. Disponível em www.abed.org.br/congresso2009/trabalhos1.asp.

20. Perez C. Signos da marca: expressividade e sensorialidade. São Paulo: Pioneira Thomson Learning; 2004.

21. Jucá F, Tortorelli F. O jogo das marcas. São Paulo: Editora Cultrix; 2008. 